\title{
Proposed Cone Calorimeter for Woven Carpet
}

\author{
Sanaa M. Enany \\ Textile Metrology Lab, National Institute for Standards, Giza, Egypt, University College of Samtah Governorate, \\ Jazan University, Jazan, Kingdom of Saudi Arabia \\ Email: Sanaa.enany@yahoo.com
}

How to cite this paper: Enany, S.M. (2019) Proposed Cone Calorimeter for Woven Carpet. Journal of Textile Science and Technology, 5, 61-68. https://doi.org/10.4236/jtst.2019.53006

Received: June 25, 2019

Accepted: August 6, 2019

Published: August 9, 2019

Copyright $\odot 2019$ by author(s) and Scientific Research Publishing Inc. This work is licensed under the Creative Commons Attribution International License (CC BY 4.0).

http://creativecommons.org/licenses/by/4.0/ (c) (i) Open Access

\begin{abstract}
It is necessary to achieve the best specifications in carpets that provide safety to human health in establishments and buildings. This can be achieved by reducing the emissions of toxic gases from combustion via controlling the carpets composition. This research presents a study on carpets behavior when burning samples with different mixing specifications to determine the combustion products by conducting a test using cone Calorimeter to determine the effect of different structures of the carpet on combustion products. The study includes the effect of both the quality of the material used and their different densities and thicknesses. The research provides an analysis of carpet combustion products from different emissions, such as the amount of carbon monoxide $\mathrm{CO}$, the amount of carbon dioxide $\mathrm{CO}_{2}$, smoke density, heat of combustion, and the heat released rate. It is clear that the rate of heat released is uneven in samples with different percentages of mixing. The samples with higher mixing percentage of synthetic fibers give lower temperature while the samples with higher wool percentage give higher temperature. The temperature of combustion increases gradually with the increase of the percentage of wool while the density of the smoke decreases which achieves the required safety of carpets. In addition to this, the research proves the increase of both $\mathrm{CO}$ and $\mathrm{CO}_{2}$ as the percentage of synthetic fibers in products which confirms the necessity to avoid the adverse effects of these emissions on human health.
\end{abstract}

\section{Keywords}

Carpets, Cone calorimeter, Combustion Products, Emissions

\section{Introduction}

Although the carpet industry is relatively a smaller source of pollution compared to the chemical industry and many other industries, it causes many toxic and choking emissions, especially when exposed to combustion. It causes harmful 
compounds such as nitrogen oxides, sulphur, toxic $\mathrm{CO}$ and $\mathrm{CO}_{2}$, hydrogen sulfide and hydrogen cyanide [1].

There are more than $60 \%$ of homes, commercial and public institutions, care homes, hospitals, hotels, reception areas and transportation, they have carpets covering the floors of these places. We can imagine the amount of chemicals that are harmful to people living in these places and even children in different life stages and extent of the risk of these chemicals on their lives and even that can be terminated because of the frequent exposure to the source of pollution without alerting people exposed to this deadly danger. Whether the carpet is new or old, it is likely that they have more harmful things than we imagine. For new carpets, there are VOC's (volatile organic compounds) - these materials contain such as toluene, benzene, formaldehyde, ethyl benzene, citrine, acetone and a group of other chemicals. Some of them have actually made a very dangerous substances list called carcinogens such as (Dichlorobenzene-p) found in new carpets as well as chemicals that cause delirium, hallucinations, nerve damage and dyspneic in humans [2]. Although the loss of homes or property is very unfortunate, the effects of fires on people are the heaviest losses at all. However, scientific studies and technical statistics issued by the agencies and organizations concerned with fire accidents in the world confirm that the deaths from burns do not exceed $3 \%$ of the victims of fires, at a time when the victims of toxic fire gases range from $42 \%$ to $50 \%$ [3]. Therefore, the toxicity of smoke from the fire is the main reason for the death of the fires in the populated areas due to the containment of smoke on many toxic gases. Hence, the importance of studying carpet combustion products is to determine the structures to help reduce the emissions from the combustion of carpets to work safely and securely. For this, several tests were conducted to measure carpet combustion products from toxic gases and heat released [4] [5]. Among these tests, there is the tunnel test where this test includes testing building interior wall and ceiling finishes with carpets for their ability to support and propagate fire, and for their tendency to emit smoke [6]. There is also a test of the radiator, which is a method to measure the amount of critical energy needed to ignite the surface of flooring furnishings using a radiant heat source [7]. In this research, we propose the test of cone Calorimeter included in the international standard to measure the amount of emissions from the combustion of carpets and to determine the type and percentage of toxic gases emitted from combustion, as well as the rate of heat released and the smoke density resulted from combustion.

\section{Experimental Work}

The test on cone calorimeter (model FTT) is based on simulating the conditions under which materials can be exposed (Figure 1). A fire occurs by exposing the samples to heat by using the cone heater and the ignition source which is the electric spark that occurs after ignition in the manner of oxygen consumption in the atmosphere of fire using an oxygen analyzer device (model 540 a). The 


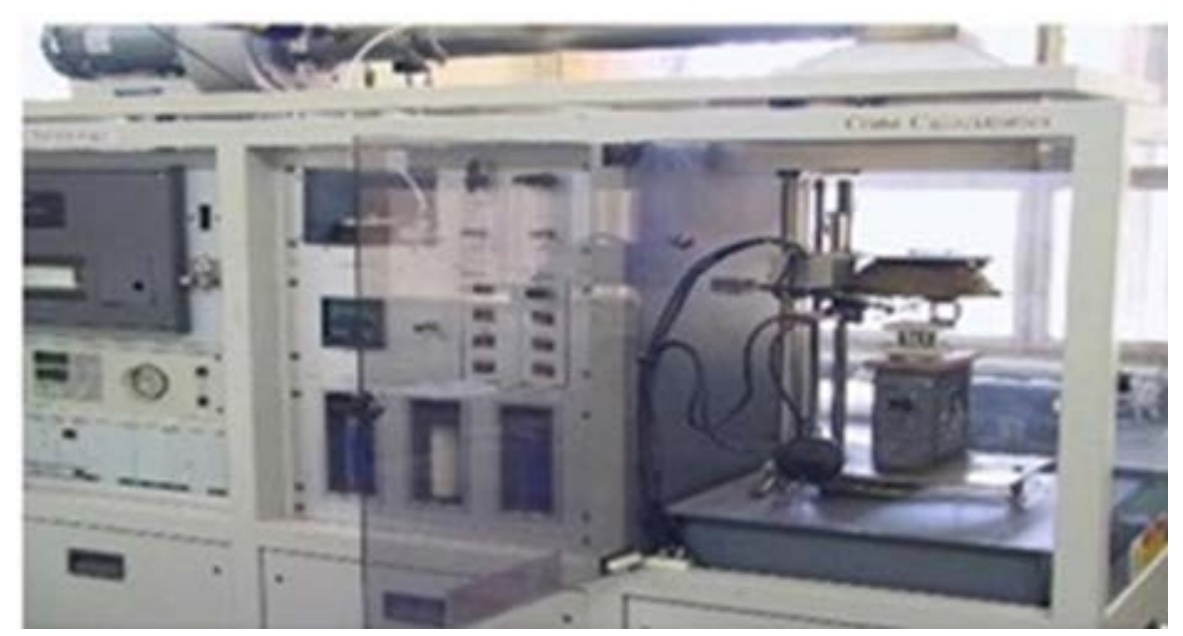

Figure 1. Cone calorimeter device.

density of the smoke emitted from the tested samples is also measured using laser technology. The cone calorimeter can isolate the different emissions automatically to analyze their amounts and percentages independently. The system uses also $\mathrm{CO}$ and $\mathrm{CO}_{2}$ gas analyzer (model Ultramat 22) to determine the percentage of the toxic gases.

Twenty-seven samples with different specifications (Figures 2(a)-(c)) were produced by Oriental Weavers Company specifically for this test, with a sample area of $100 \mathrm{~cm}^{2}$ (10 cm for width and $10 \mathrm{~cm}$ for length) as shown in Figure 3. The carpet sample was of jute type background, yarm count 10/3 wool-6000 denier, 32 rows per $10 \mathrm{~cm}$, open terry, and 33 (door/10 cm) comb kit.

In the beginning, the sample was weighed and its thickness was determined before testing. The distance between the conical radiation source and the sample was adjusted and then the device was turned on and the sample was placed inside it to perform the incineration process according to the standard specification (STM E 1454 or ISO 5660).

When the sample reached the ignition both $\mathrm{CO}, \mathrm{CO}_{2}$ and other gases, as well as smoke, were emitted and heat released (Figure 4). The emissions were analyzed by the oxygen analyzer and the $\mathrm{CO}, \mathrm{CO}_{2}$ analyzer.

\section{Results and Discussion}

Figure 5(a) shows the results of the heat released from the combustion of the various samples and the smoke density. The combustion heat is shown in Figure 5 (b), while the ratio of $\mathrm{CO}$ and $\mathrm{CO}_{2}$ gases analyzed by the device are shown in Figure 5(c).

From Figure 5, it is clear that the rate of the released heat is variable in samples with different percentages of mixing. But from most of the sample results, we find that samples with higher mixing percentages of synthetic fibers give lower heat released as shown in the results of samples $(1,2,3,8,9,11,13,14,15$, 16). 


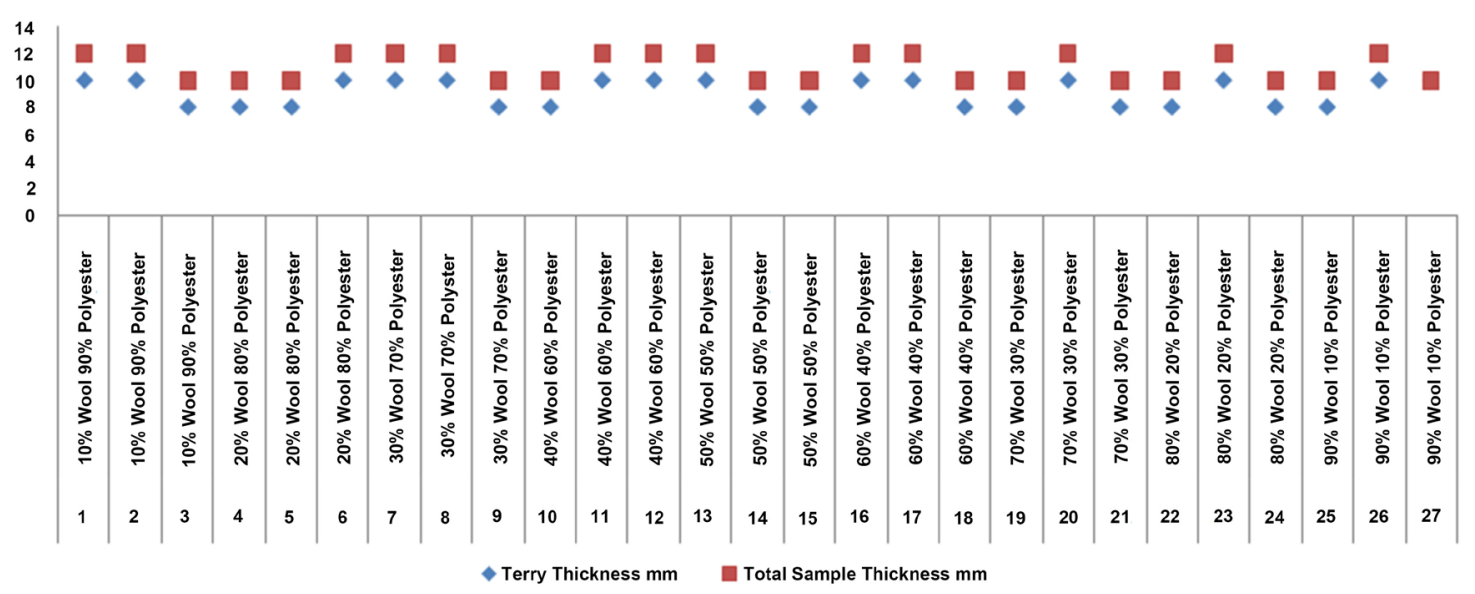

(a)

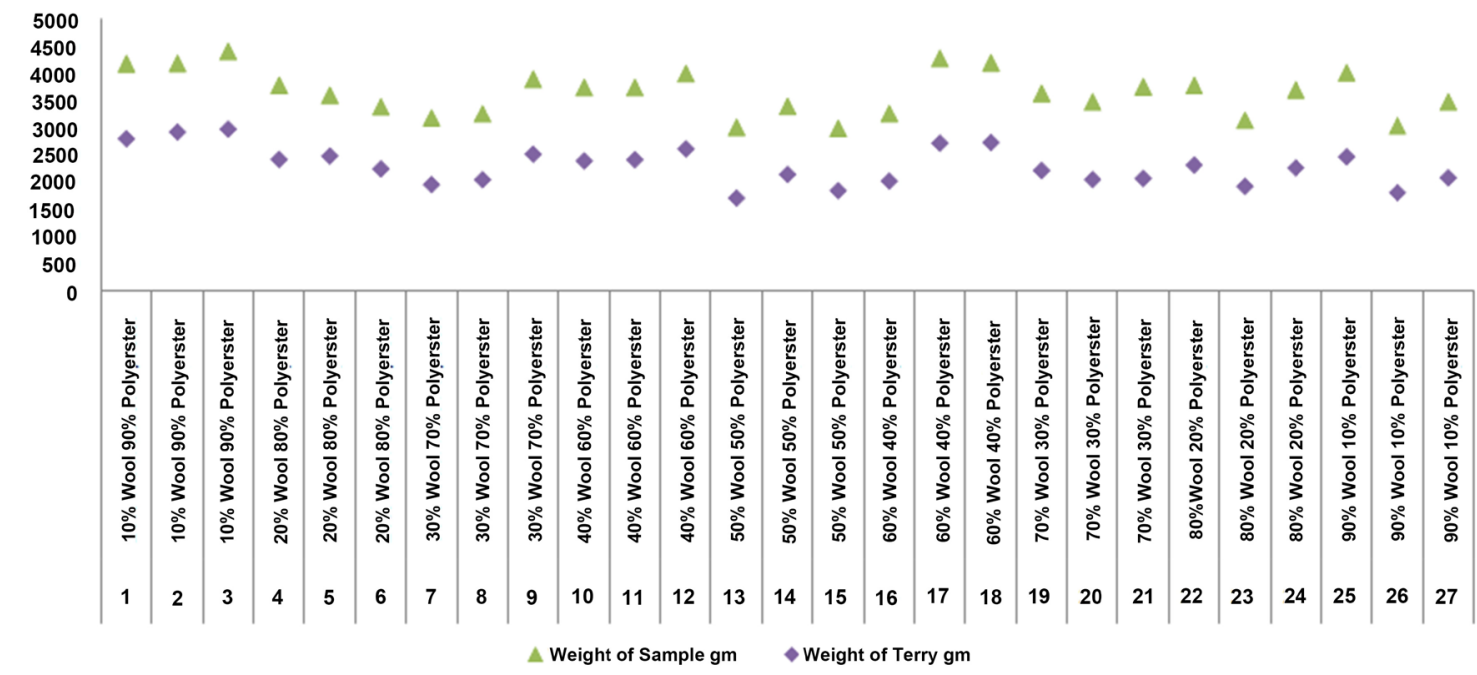

(b)

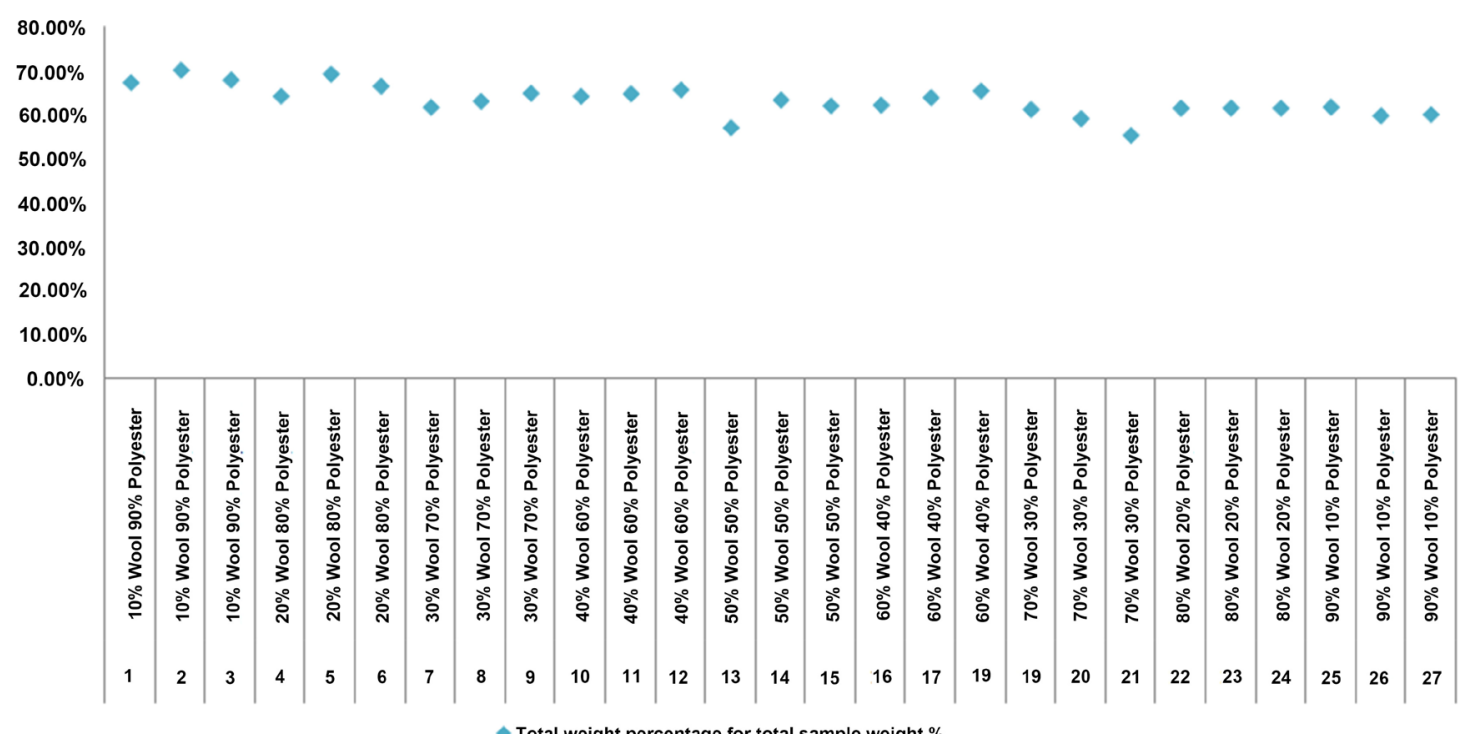

(c)

Figure 2. Specification of samples used in cone calorimeter test. 


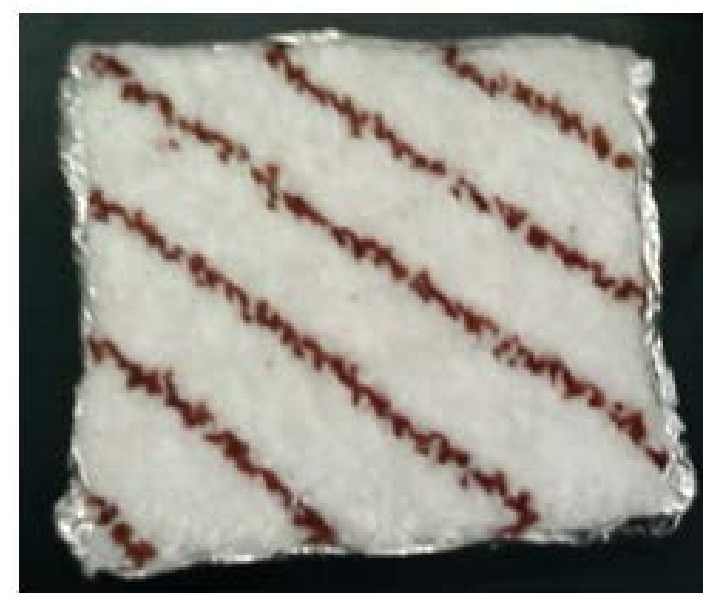

Figure 3. Sample in the ordinary case (before test).

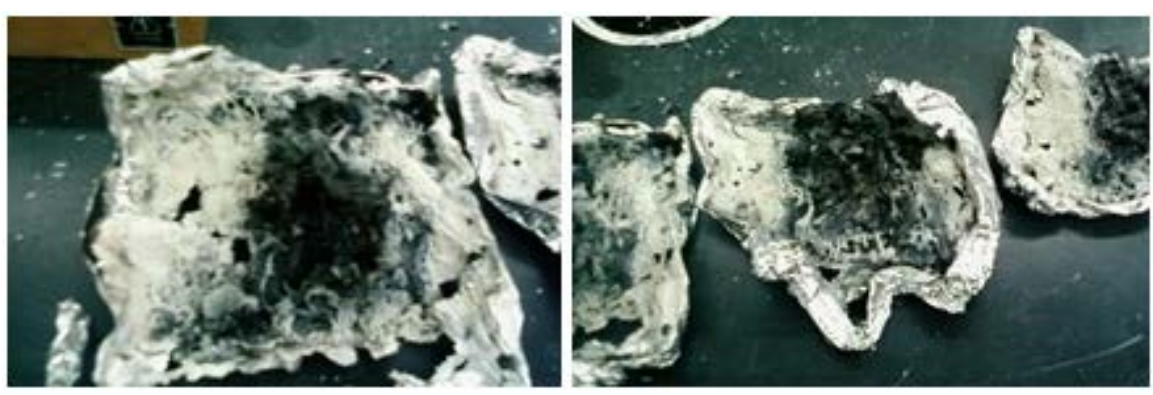

Figure 4. Sample after exposed to fire and ignition (after test).

Samples with higher wool ratios give more released heat because the wool is inflammable and therefore the heat starts from it at the moment of ignition. In case of synthetic fibers, it does not ignite at the moment of exposure to flame, but takes time until its melting, which helps it to continue its ignition and therefore does not release the heat from the moment of exposure to flame.

It is also clear that the lower the combustion heat the better is the sample mixing. The samples with mixing ratios of $50 \%$ wool $50 \%$ polyester to $90 \%$ wool $10 \%$ polyester give combustion heat from $18.57(\mathrm{Mg} / \mathrm{kg})$ to $19.801(\mathrm{Mg} / \mathrm{kg})$. While the samples with mixing ratios of $40 \%$ wool $60 \%$ polyester to $10 \%$ wool $90 \%$ polyester give combustion heat relatively less than $17.124(\mathrm{Mg} / \mathrm{kg})$ to 19.462 $(\mathrm{Mg} / \mathrm{kg})$ due to the increase in the percentage of synthetic fibers.

As for the density of the smoke, it is observed that the samples with mixing ratios $40 \%$ wool $60 \%$ polyester to $10 \%$ wool $90 \%$ polyester produce a smoke density of $469.319 \mathrm{~m}^{2} / \mathrm{kg}$ to $620.249 \mathrm{~m}^{2} / \mathrm{kg}$. But samples with mixing ratios $50 \%$ wool $50 \%$ polyester to $90 \%$ wool $10 \%$ polyester produce a smoke density ranging from $224.283\left(\mathrm{M}^{2} / \mathrm{kg}\right)$ to $380.973\left(\mathrm{M}^{2} / \mathrm{kg}\right)$.

On the other hand, the smoke density by the samples with mixing ratio of $50 \%$ wool $50 \%$ polyester is less than the smoke density of by the samples with mixing of $40 \%$ wool $60 \%$ polyester to $10 \%$ wool $90 \%$ polyester. This indicates that the higher percentage of wool the less the smoke density resulting from 
combustion. Thus mixing $50 \%$ wool $50 \%$ polyester has achieves the required safety carpets specifications.

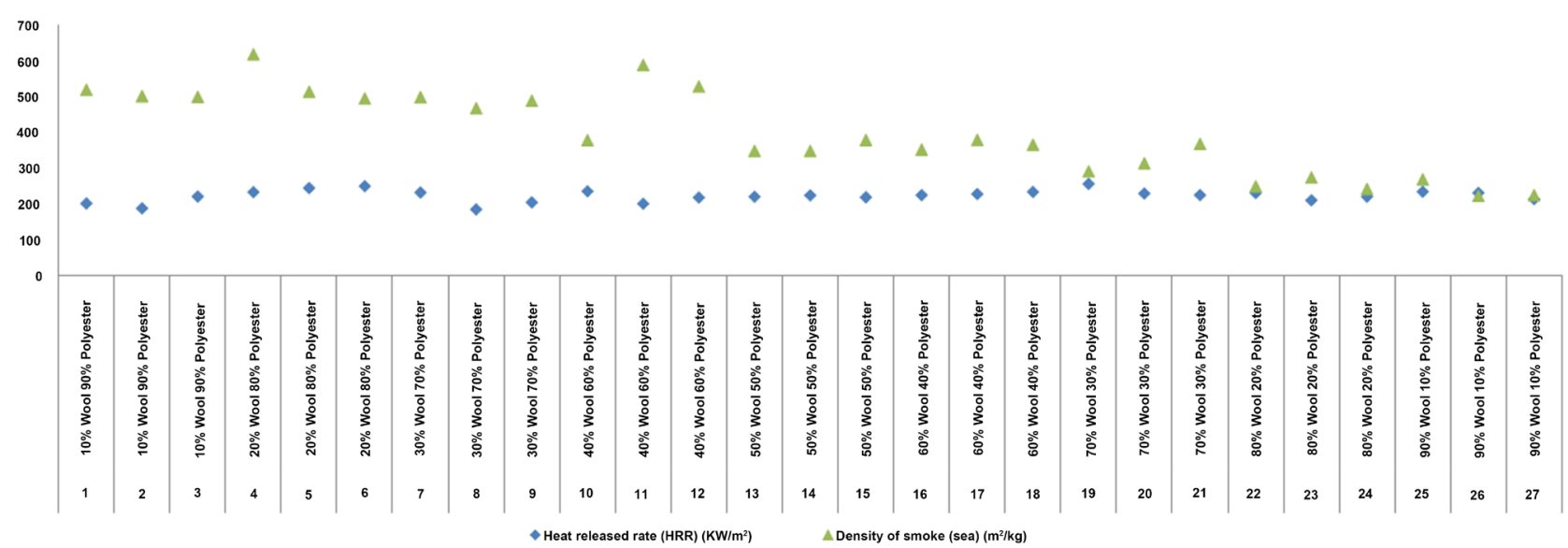

(a)

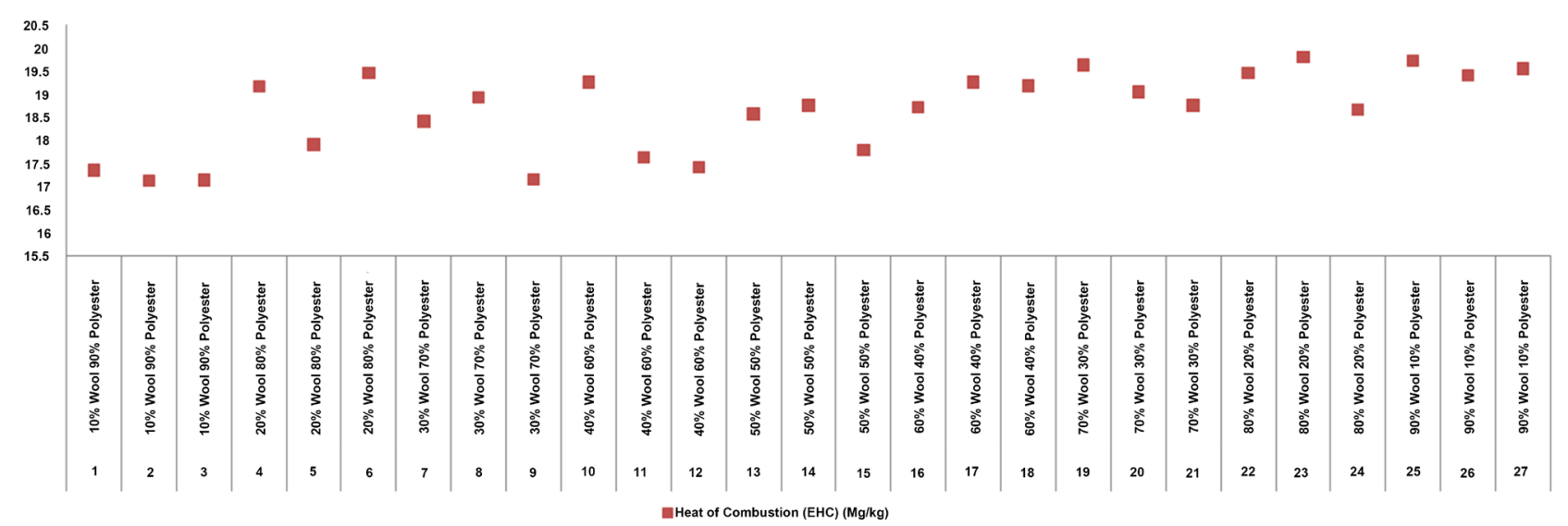

(b)

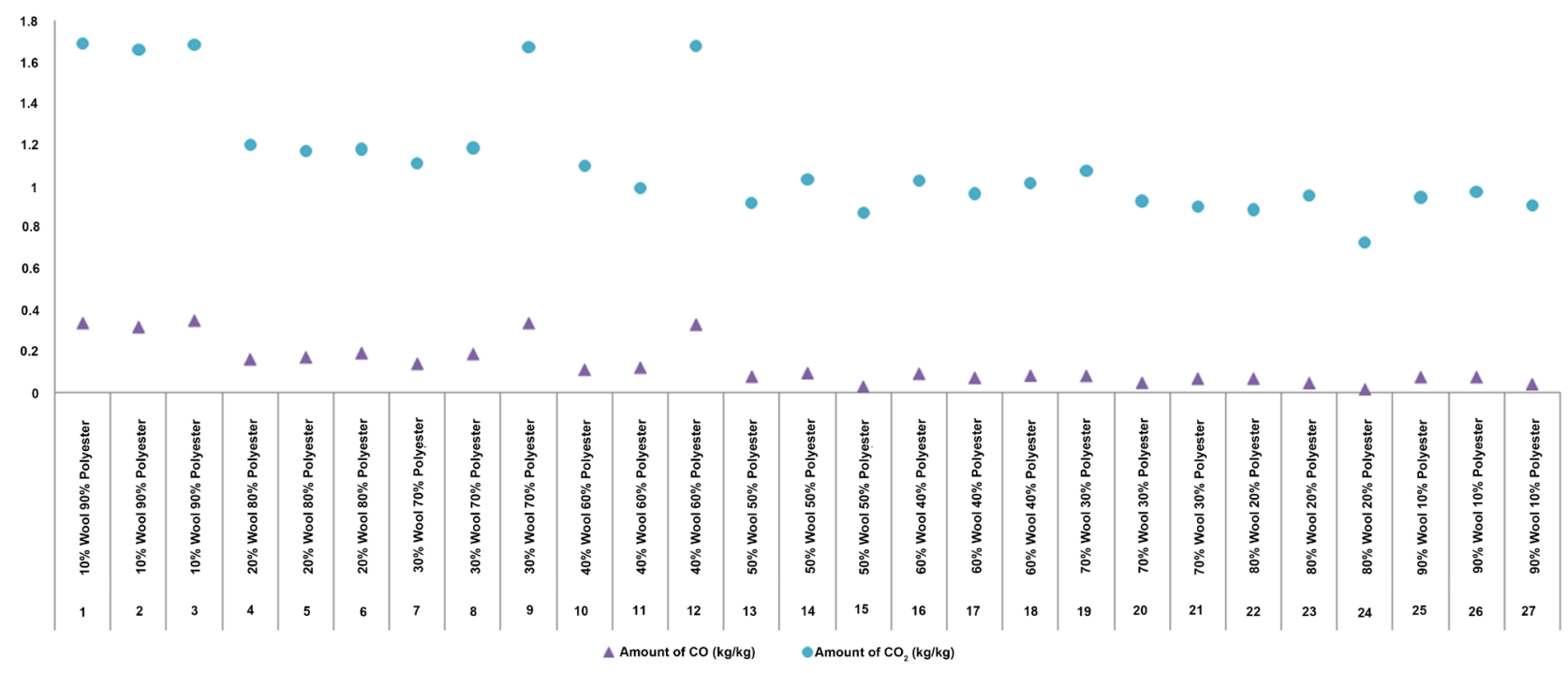

(c)

Figure 5. Results of the analysis of the rate of released heat, combustion heat, smoke density, $\mathrm{CO}$ and $\mathrm{CO}_{2}$. 
One of the most important advantages of the cone calorimeter is the ability to determine the amount of $\mathrm{CO}$ because of the importance to eliminate it for human safety. Therefore, the results can be divided into two parts. The first shows that the ratio of gas in samples with wool ratio from $50 \%$ to $90 \%$ ranges between $0.015(\mathrm{~kg} / \mathrm{kg})$ to $0.094(\mathrm{~kg} / \mathrm{kg})$, while the second part shows that the ratio of gas in samples with wool ratio from $10 \%$ to $40 \%$ ranges between $0.11(\mathrm{~kg} / \mathrm{kg})$ to $0.348(\mathrm{~kg} / \mathrm{kg})$.

Thus, it is shown that the amount of emitted CO is much less for the mixing ratio $50 \%$ wool $50 \%$ polyester and this proves that the higher the percentage of synthetic fibers in products the higher the severity is due to the increased toxic gas escalation of $\mathrm{CO}$.

In addition, Figure 5 shows that the percentage of gas in samples with wool ratio from $50 \%$ to $90 \%$ ranges between $0.725(\mathrm{~kg} / \mathrm{kg})$ to $1.073(\mathrm{~kg} / \mathrm{kg})$ while for samples with wool ratio from $10 \%$ to $40 \%$ it ranges from $1.096(\mathrm{~kg} / \mathrm{kg})$ to 1.688 $(\mathrm{kg} / \mathrm{kg})$, which means, the higher the percentage of synthetic fibers in products, the higher severity is due to the increased emitted carbon dioxide $\left(\mathrm{CO}_{2}\right)$ gas. Thus the amount of $\mathrm{CO}_{2}$ is quite lower for the higher mixing ratios of polyester.

\section{Conclusion}

In this research, the emissions from the combustion of carpets were measured to determine the best mixing ratios of fibers in carpets for human safety. And 27 samples with different mixing fibers were tested on the cone calorimeter under simulated conditions to measure the released heat, combustion heat, smoke density, $\mathrm{CO}$, and $\mathrm{CO}_{2}$ and to estimate the best mixing fiber ratios in carpets. From the experimental and analytical work, it was proven that the samples with the mixing of $50 \%$ wool $50 \%$ polyester which reduced the emissions from the combustion have achieved the required conditions of carpets mixing for human safety. This guided us to recommend the use of carpets of higher structural composition than wool fibers.

\section{Conflicts of Interest}

The author declares no conflicts of interest regarding the publication of this paper.

\section{References}

[1] Malik, A.S., Boyko, O., Atkar, N. and Young, W.F. (2001) A Comparative Study of MR Imaging Profile of Titanium Pedicle Screws. Acta Radiologica, 42, 291-293. http://dx.doi.org/10.1080/028418501127346846

[2] Hu, T. and Desai, J.P. (2004) Soft-Tissue Material Properties under Large Deformation: Strain Rate Effect. Proceedings of the 26th Annual International Conference of the IEEE EMBS, San Francisco, 1-5 September 2004, 2758-2761.

[3] Ortega, R., Loria, A. and Kelly, R. (1995) A Semiglobally Stable Output Feedback $\mathrm{PI} /$ sup 2/D Regulator for Robot Manipulators. IEEE Transactions on Automatic Control, 40, 1432-1436. http://dx.doi.org/10.1109/9.402235 
[4] Wit, E. and McClure, J. (2004) Statistics for Microarrays: Design, Analysis, and Inference. 5th Edition, John Wiley \& Sons Ltd., Chichester.

[5] Prasad, A.S. (1982) Clinical and Biochemical Spectrum of Zinc Deficiency in Human Subjects. In: Prasad, A.S., Ed., Clinical, Biochemical and Nutritional Aspects of Trace Elements, Alan R. Liss, Inc., New York, 5-15.

[6] Giambastiani, B.M.S. (2007) Evoluzione Idrologica ed Idrogeologica Della Pineta di san Vitale (Ravenna). Ph.D. Thesis, Bologna University, Bologna.

[7] Wu, J.K. (1994) Two Problems of Computer Mechanics Program System. Proceedings of Finite Element Analysis and CAD, Peking University Press, Beijing, 9-15. 